\title{
SIMULAÇÃO DA SOJA GENETICAMENTE MODIFICADA TOLERANTE AO GLYPHOSATE POR MEIO DO CULTIVO DE EXPLANTES ${ }^{1}$
}

\author{
SÉRGIO C. SIQUEIRA ${ }^{2}$, MAURÍLIO A. MOREIRA ${ }^{3}$, PAULO R. MOSQUIM ${ }^{4}$, INÊS C. JOSÉ ${ }^{5}$, FRANCISCO A. FERREIRA ${ }^{6}$ e \\ CARLOS S. SEDIYAMA ${ }^{6}$
}

\section{RESUMO}

O objetivo do experimento consistiu na simulação in vitro da soja transgênica tolerante ao glyphosate, através do cultivo de explantes em meios de cultura contendo aminoácidos aromáticos. As avaliações basearam-se nos efeitos do glyphosate sobre sementes oriundas de explantes de soja (Glycine $\max$ (L.) Merr.) cv. UFV-16. Para tanto, explantes de soja foram cultivados em meios de cultura líquidos com $\mathrm{pH}$ em torno de 5,0. Cada explante constou de um legume completamente expandido contendo duas sementes de aproximadamente $100 \mathrm{mg}$, conectada a um segmento de caule de $45 \mathrm{~mm}$ de comprimento. Os tratamentos testados foram: $\mathrm{A}=$ glutamina $(\mathrm{Gln}) ; \mathrm{B}=\mathrm{Gln}+$ fenilalanina $(\mathrm{Phe})+$ tirosina $(\mathrm{Tyr})+$ triptofano (Trp); C = Gln + glyphosate; D = Gln + Phe + Tyr
+ Trp + glyphosate. O experimento foi conduzido sob irradiância de $80 \mu \mathrm{mol}^{-2} \mathrm{~s}^{-1}$ a $25^{\circ} \mathrm{C}$ por 204 horas. Nos tratamentos que receberam aminoácidos aromáticos e glutamina, o herbicida não afetou as massas fresca e seca das sementes, como também, não afetou seus constituintes bioquímicos (proteínas, óleo, ácidos graxos, carboidratos e clorofilas). Portanto, a suplementação exógena de aminoácidos aromáticos suprime os efeitos fitotóxicos do glyphosate sobre explantes de soja, permitindo estudos sobre o seu modo de ação e metabolismo nas sementes, uma vez que os explantes se comportaram analogamente à soja transgênica não suscetível ao herbicida.

Palavras chave: Glycine max, cultivo in vitro, do shiquimato, aminoácidos aromáticos.

\section{ABSTRACT}

\section{Simulation of the transgenic soybean tolerant to glyphosate through explant cultivation}

The objective of this experiment consisted in simulation in vitro of the transgenic soybean tolerant to glyphosate through explant cultivation in culture medium containing aromatic amino acids. The effects of glyphosate on soybean (Glycine $\max$ (L.) Merrill) were evaluated in seeds harvested from explants of cv UFV-16. The soybean explants were cultivated in liquid medium culture with $\mathrm{pH}$ about 5.0. Each explant consisted of one fruit completely expanded, containing two seeds of $100 \mathrm{mg}$ approximately, and connected to a stem segment of $45 \mathrm{~mm}$ length. The explants were submitted to the following treatments: $\mathrm{A}=$ glutamine $(\mathrm{Gln}) ; \mathrm{B}=\mathrm{Gln}+$ phenylalanine $(\mathrm{Phe})+$ tyrosine $($ Try) + tryptophan (Trp); C = Gln + glyphosate; D = Gln + Phe + Tyr $+\operatorname{Trp}+$ glyphosate. The experiment was conducted under irradiance of $80 \mu^{-m^{-2} \mathrm{~s}^{-1}}$ at $25^{\circ} \mathrm{C}$ for 204 hours. The treatments with aromatic amino acids and glutamine avoided the herbicide effect on seed fresh and dried weights

\footnotetext{
${ }^{1}$ Recebido para publicação em 25/11/97 e na forma revisada em 07/08/98.

${ }^{2}$ Estudante de Doutorado do Dept ${ }^{\mathrm{o}}$ de Fitotecnia da UFV, BIOAGRO. CEP 36571-000, Viçosa/MG.

${ }^{3}$ Professor Titular, Ph.D., Dept ${ }^{\circ}$ de Bioquímica e Biologia Molecular da UFV, BIOAGRO. CEP 36571-000, Viçosa/MG.

${ }^{4}$ Professor Titular, D.S., Dept ${ }^{\circ}$ de Biologia Vegetal da UFV. CEP 36571-000, Viçosa/MG.

${ }^{5}$ Pesquisadora, M.S., Núcleo de Biotecnologia Aplicada à Agropecuária da UFV. CEP 36571-000, Viçosa/MG.

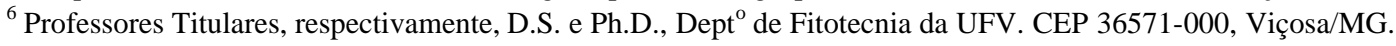


and had no effect on their biochemical constituents (proteins, oil, fatty acids, carbohydrates and chlorophylls). Thus, an exogenous supplementation of aromatic amino acids eliminates phytotoxic effects of glyphosate on soybean explants. Therefore, it was developed an in vitro system that allows to

\section{INTRODUÇÃO}

A iminente introdução de variedades de soja geneticamente modificadas e tolerantes ao glyphosate, no Brasil, à semelhança do que ocorreu nos EUA, exige técnicas de avaliação preliminares, sob condições padronizadas, que se prestem a testar graus de tolerância dessas variedades ao glyphosate. A tolerância, nesse caso, é estimada por meio dos reflexos do herbicida no conteúdo e na composição dos constituintes bioquímicos das sementes de soja.

O glyphosate é um eficiente inibidor da enzima EPSPS (5-enolpiruvilshiquimato-3-fosfato sintase; E.C. 2.5.1.19), uma das envolvidas na rota biossintética dos aminoácidos aromáticos ou, simplesmente, rota do shiquimato. A soja geneticamente modificada codifica uma variante da EPSPS, que possui baixa afinidade ao glyphosate, conferindo a ela tolerância ao herbicida (Harrison et al., 1995).

A meta proposta para esses experimentos foi simular, fisiologicamente, o comportamento da soja tolerante ao glyphosate, a partir da soja suscetível a ele. Para tanto, explantes de soja foram cultivados em meios de cultura líquidos, sob condições semi-assépticas, contendo nutrientes minerais, glutamina, sacarose e glyphosate. As tentativas de simulação deram-se pelo fornecimento exógeno de fenilalanina, tirosina e triptofano aos meios de cultivo em que os explantes foram cultivados, com o propósito de compensar a depressão dos níveis desses aminoácidos aromáticos, acarretada pela inibição da enzima EPSPS pelo herbicida.

Este trabalho objetivou, especificamente, verificar os efeitos do glyphosate sobre o study the mode of action and the metabolism of glyphosate in soybean seeds, since the explants behaved in a similar manner as the transgenic soybean unsusceptible to the herbicide.

Key words: Glycine max, in vitro culture, shikimate pathway, aromatic amino acids, seed composition.

conteúdo e sobre a composição de proteína, óleo, carboidratos e clorofilas de sementes oriundas de explantes de soja, cultivados em diferentes meios de cultura líquidos, pois, segundo Devine et al. (1993), estes são os principais constituintes bioquímicos afetados pelo glyphosate, em plantas.

\section{MATERIAL E MÉTODOS}

Neste trabalho, conduzido no período de 1996 a 1997, foram utilizadas sementes de soja (Glycine max [L.] Merr. cv. UFV-16), fornecidas pelo Núcleo de Biotecnologia Aplicada à Agropecuária (BIOAGRO) da Universidade Federal de Viçosa, Viçosa (MG). As sementes foram semeadas em vasos de polietileno com capacidade para 3 litros, contendo como substrato, areia previamente lavada com ácido muriático e tratada com brometo de metila. As plântulas obtidas foram mantidas em casa-de-vegetação sob condições naturais de luz, temperatura e umidade relativa. Após 10 dias, quando as plântulas apresentaram o primeiro trifólio completamente expandido, foi efetuado desbaste, deixando-se apenas duas plantas por vaso. Estas foram irrigadas diariamente e, duas vezes por semana, foram aplicados $200 \mathrm{ml}$ de solução nutritiva completa de Hoagland (Hoagland \& Arnon, 1950). As plantas permaneceram nestas condições até apresentarem o pericarpo completamente formado e as sementes ocupando todo o lúmen dos legumes, com biomassa fresca em torno de 100 mg cada. Quando as sementes apresentaram a matéria fresca relatada, as plantas foram transferidas para laboratório para instalação do experimento de cultivo in vitro das sementes de soja, mantendo-se plantas in situ como controle. 
O cultivo de explantes em condições semi-assépticas seguiu a metodologia descrita por Mosquim \& Sodek (1991). Cada explante era constituído de um legume completamente expandido, contendo duas sementes de aproximadamente $100 \mathrm{mg}$, conectada a um segmento de caule de $45 \mathrm{~mm}$ de comprimento. Os explantes foram excisados a partir do quinto nó da base para o ápice.

Os explantes foram cultivados em meios de cultura líquidos, com volumes de $6,5 \mathrm{ml}$, preparados segundo Chandler et al. (1983) para os macronutrientes e Thompson et al. (1977) para os micronutrientes. A solução de ferro foi preparada à parte. Como fontes de nitrogênio foram utilizados glutamina (Gln), fenilalanina (Phe), tirosina (Tyr) e triptofano (Trp). Como fonte de carboidratos utilizou-se sacarose a 5\%.

Por ocasião da instalação destes experimentos, o sistema in vitro de cultivo de explantes já se encontrava previamente otimizado pelos autores para testes com o herbicida glyphosate. As concentrações de aminoácidos empregadas, isoladas ou combinadas, são aquelas que conferem maior crescimento das sementes e a dose ministrada do herbicida é aquela a partir da qual a inibição do crescimento dos grãos é máxima. Por conseguinte, foram avaliados os seguintes tratamentos: $\mathrm{A}=\mathrm{Gln}\left[1,2 \mathrm{mg} \mathrm{N} \mathrm{ml}^{-1}\right]$; $\mathrm{B}$ $=$ Gln $\left[0,9 \mathrm{mg} \mathrm{N} \mathrm{ml}^{-1}\right]+$ Phe, Tyr e Trp $[0,3 \mathrm{mg} \mathrm{N}$ $\left.\mathrm{ml}^{-1}\right] ; \quad \mathrm{C}=\mathrm{Gln}\left[1,2 \mathrm{mg} \mathrm{N} \mathrm{ml}{ }^{-1}\right]+25 \mu \mathrm{M}$ glyphosate; $\mathrm{D}=\mathrm{Gln}\left[0,9 \mathrm{mg} \mathrm{N} \mathrm{ml}^{-1}\right]+$ Phe, Tyr e $\operatorname{Trp}\left[0.3 \mathrm{mg} \mathrm{N} \mathrm{mI}^{-1}\right]+25 \mu \mathrm{M}$ glyphosate

$\mathrm{O} \mathrm{pH}$ da solução nutritiva foi mantido em torno de 5,0. O herbicida foi adicionado 36 horas após a instalação do experimento. $\mathrm{O}$ período de cultivo foi de 204 horas, mantendo-se os explantes sob nível de irradiância de $80 \mu \mathrm{mol}$ de fótons $\mathrm{m}^{-2} \mathrm{~s}^{-1}$ e temperatura de $25^{\circ} \mathrm{C}$.

Os legumes colhidos foram debulhados e as massas frescas das sementes correspondentes a cada repetição foram determinadas em seguida. Imediatamente após, as sementes foram congeladas em nitrogênio líquido e liofilizadas. Consumado o processo de liofilização, as sementes foram colocadas em dessecador e novamente pesadas para obtenção de massa seca e, na seqüência, trituradas em moinho tipo "willey" munido de peneira com malha 40. As sementes moídas foram acondicionadas em recipientes de vidro com tampas de rosca e armazenados em "freezer" a $-80{ }^{\circ} \mathrm{C}$ até a ocasião das análises bioquímicas.

Os teores de açúcares solúveis totais foram determinados pela reação com o reagente de antrona (Hodge \& Hodfreiter, 1962), e os açúcares redutores, conforme metodologia descrita por Nelson (1944) e Somogy (1952). Os açúcares nãoredutores foram estimados pela diferença entre os teores de açúcares solúveis totais e açúcares redutores. $\mathrm{O}$ amido foi também determinado pela reação com o reagente de antrona segundo Hodge $\&$ Hodfreiter (1962).

As clorofilas foram extraídas em acetona $80 \%$ (10 ml por unidade experimental composta de 14 sementes) e quantificadas de acordo com os comprimentos de onda e coeficientes de extinção propostos por Lichtenthaler (1987).

Os teores de lipídios foram determinados por meio de extração contínua das amostras em aparelho de Soxhlet, utilizando-se éter de petróleo como solvente extrator. Concluído o processo de extração, as amostras foram secas em estufa a $105^{\circ} \mathrm{C}$ até peso constante. $\mathrm{O}$ método gravimétrico utilizado foi adaptado dos procedimentos descritos em "Instituto Adolfo Lutz" (1985), com refluxo por 10 horas. Os teores de lipídios foram obtidos pela diferença de peso dos balões de extração de antes de iniciado o processo de extração e de depois da secagem.

A composição de ácidos graxos da fração lipídica das sementes foi determinada por cromatografia gasosa conforme Bubeck et al. (1989). As amostras foram injetadas num cromatógrafo a gás, modelo GC17A (Shimadzu), equipado com integrador CR-7A. Foi utilizada uma coluna Carbowax $(0,32 \mathrm{~mm}$ de diâmetro interno $\mathrm{x} 30 \mathrm{~m}$ de comprimento). As programações da coluna, do injetor e do detector, foram isotérmicas a $225^{\circ} \mathrm{C}, 240^{\circ} \mathrm{C}$ e $280^{\circ} \mathrm{C}$, respectivamente. O fluxo do gás de arraste foi de de $1,1 \mathrm{ml} / \mathrm{min}$.

Os teores de proteínas foram determinados pelo método de Kjeldahl para 
quantificação de nitrogênio total, descrito pela Association of Official Analytical Chemists AOAC (1975), com modificações. Na fase de digestão, após obtenção do material aparentemente digerido, foi adicionado peróxido de hidrogênio a 30\%, levando-se a mistura ao aquecimento por mais 30 minutos. $\mathrm{Na}$ fase de destilação, a amônia liberada foi recolhida em solução de ácido bórico a $4 \%$. No cálculo de conversão de nitrogênio em proteína, foi utilizado o fator 6,25 .

Os polipeptídeos foram separados em géis de poliacrilamida em gradiente de 10 a $18 \%$ contendo 4,42 a $5,45 \mathrm{M}$ de uréia (Fontes et al., 1984). Os polipeptídeos, uma vez separados, foram revelados com "Coomassie Brilliant Blue" R-250 em metanol:ácido-acético:água (45:9:46 $\mathrm{v} / \mathrm{v} / \mathrm{v})$, sendo o gel descolorido com metanol:ácido-acético:água (25:7,5:67,5 v/v/v). A imagem do gel foi fotodocumentada em equipamento Eagle Eye II (Stratagene), e analisada com "software" One Dscan (Scanalytics). As densidades relativas de cada banda protéica foram computadas com quatro repetições e suas proporções estimadas com base na proteína total.

$\mathrm{O}$ delineamento experimental foi $\mathrm{o}$ inteiramente casualizado com quatro repetições, sendo cada unidade experimental composta de sete explantes, com um total de catorze sementes. As análises de laboratório foram realizadas em quatro repetições por unidade experimental. As médias obtidas foram comparadas pelo teste de Tukey a um nível de 5\% de probabilidade. Para análise de variância e teste de médias, foi utilizado o Sistema para Análise Estatística e Genética (Euclides, 1982).

\section{RESULTADOS E DISCUSSÃO}

Os resultados dos experimentos demonstraram que há maior crescimento das sementes in vitro do que in situ. Verificou-se que, na presença de aminoácidos aromáticos, o glyphosate, na dose ministrada, não exerce fitotoxicidade sobre os explantes, não afetando, portanto, os constituintes bioquímicos das sementes.

O herbicida dessecou as sementes de soja no tratamento isento de aminoácidos aromáticos (Figura 1). $\mathrm{O}$ incremento de matéria seca do tratamento contendo glutamina mais glyphosate, foi inferior no tratamento contendo aminoácidos aromáticos e glyphosate. Este tratamento não diferiu dos tratamentos sem o herbicida, tendo sido superior ao controle in situ.

Conforme se observa na Figura 1, houve incremento significativo de matéria seca das sementes do tratamento com glutamina mais glyphosate em relação ao do controle "inicial", porém muito aquém dos demais tratamentos. Esse fato pode ser atribuído ao rápido influxo do glyphosate, a partir do meio de cultivo, para os seus sítios primários de ação nos explantes, associado à inabilidade de os caules e pericarpos mobilizarem suas limitadas reservas protéicas para as sementes em formação. As sementes dos explantes, por ocasião da instalação dos experimentos, encontravam-se em estádio de enchimento e em intensa biossíntese de proteínas de reserva.

A hidrólise e a posterior mobilização das proteínas desses dois órgãos (caules e pericarpos), supostamente, supririam os tecidos dos explantes de aminoácidos aromáticos, tanto quanto atenderiam à demanda das sementes por esses compostos. Tal possibilidade, se concreta, atenuaria, sobremaneira, os efeitos "fitotóxicos" desse herbicida, mas isto não se observou de fato.

De acordo com Margna et al. (1989), em plantas intactas, contrariamente a explantes, a diminuição do conteúdo de aminoácidos aromáticos é menor do que se espera. Tais plantas, quando tratadas com glyphosate, são capazes de obter aminoácidos aromáticos pela hidrólise de proteínas contidas nos seus diversos órgãos e no pool desses aminoácidos, na sua forma livre e armazenados nos vacúolos, como também sintetizá-los por meio da rota do shiquimato, ainda que em quantidades mínimas.

O tratamento com glutamina, sem o herbicida, apresentou maior teor de proteína total nas sementes em relação ao tratamento com glutamina e aminoácidos aromáticos (Figura 2). 


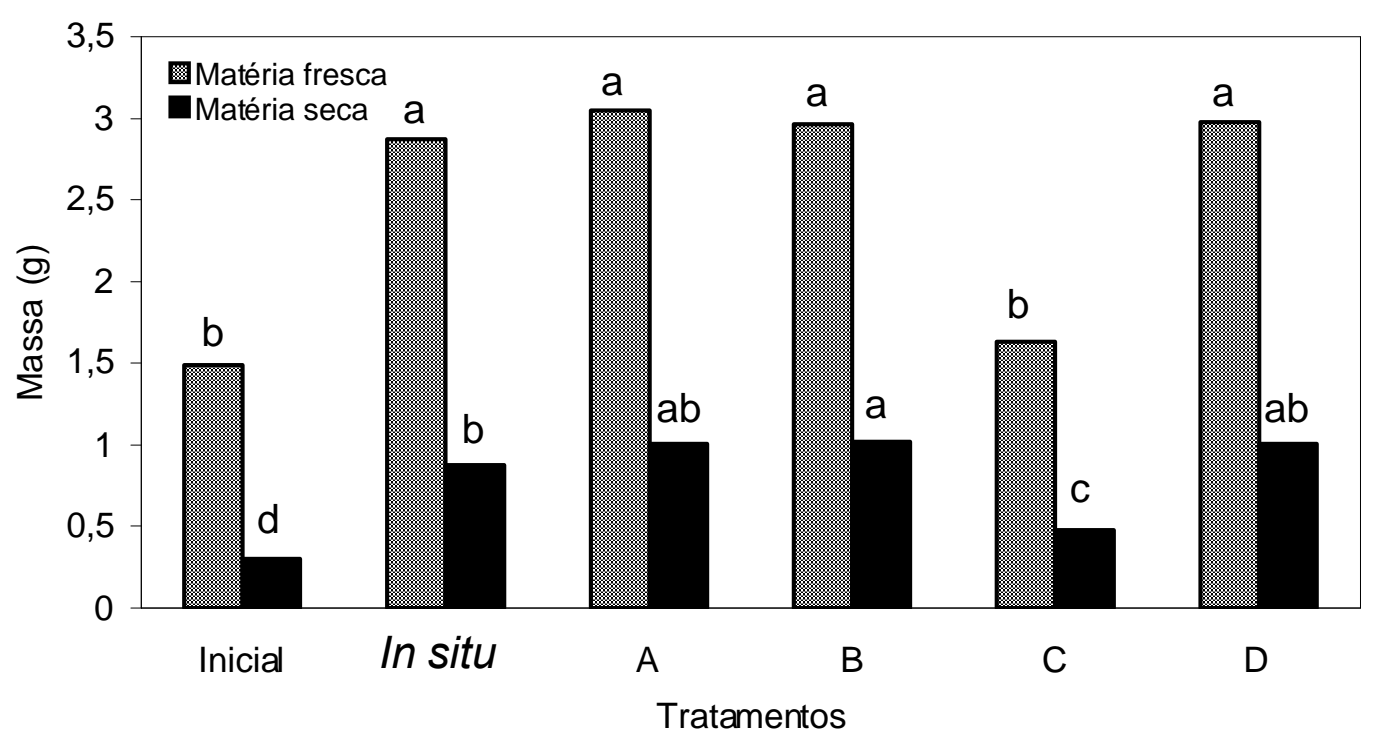

FIGURA 1. Incremento das matérias fresca e seca de sementes de explantes de soja cultivados em meios de cultura por 204 horas. Barras com mesmas letras entre tratamentos não diferem entre si pelo teste de Tukey $(\mathrm{P}>0,05)$.

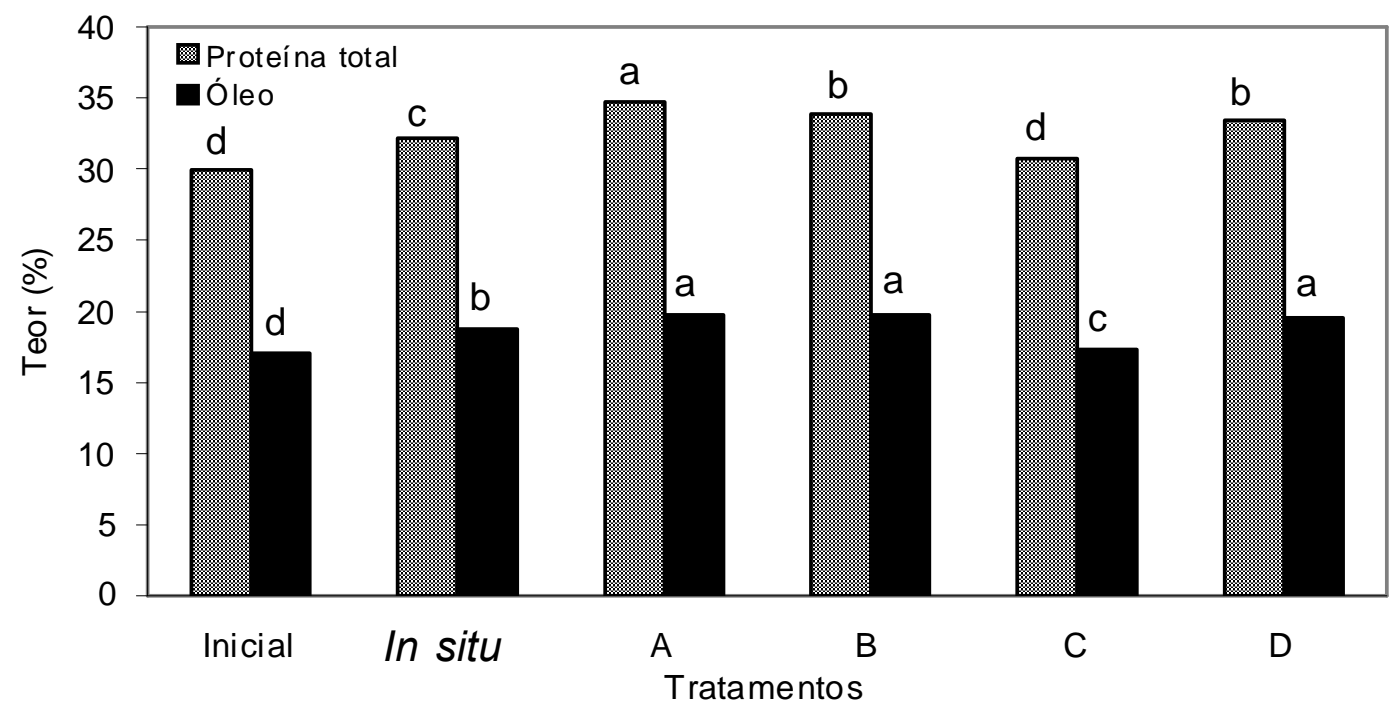

FIGURA 2. Teores de proteína e óleo de sementes de explantes de soja cultivados em meios de cultura por 204 horas. Barras com mesmas letras entre tratamentos não diferem entre si pelo teste de Tukey $(\mathrm{P}>0,05)$. 
Esse resultado vem confirmar o sistema em estudo como sendo um reflexo da planta in situ, pois a glutamina é a principal fonte de nitrogênio utilizada na síntese de proteínas de reserva nos cotilédones (Mosquim e Sodek, 1991).

$\mathrm{O}$ tratamento com glutamina mais glyphosate, na dose-padrão de trabalho (Figura 2), promoveu redução drástica do teor protéico das sementes pela ação do herbicida. O teor protéico das sementes do tratamento com glutamina mais aminoácidos aromáticos não foi afetado pelo glyphosate, fato esse que concorda com as observações de Duke e Hoagland (1981). Segundo esses autores, os efeitos "fitotóxicos" do glyphosate em plântulas de soja podem ser parcialmente revertidos pelo fornecimento exógeno de aminoácidos aromáticos às raízes, apesar de a maior parte desses aminoácidos ficar retida na periderme, nas células do córtex e na endoderme desse órgão responsável por absorção.

Ao contrário de plantas intactas, os explantes são destituídos das barreiras anatômicas próprias da absorção radicular. A solução nutritiva contendo aminoácidos aromáticos é absorvida, diretamente, pelo xilema, ocorrendo translocação até os frutos. Nesse caso, não se trata de reversão dos efeitos "fitotóxicos" do glyphosate em tecidos lesionados, mas sim de prevenção continuada desses efeitos sobre os explantes de soja, pelo fornecimento antecipado dos produtos finais da rota do shiquimato, que é o sítio primário de ação desse herbicida.

A prevenção dos efeitos "fitotóxicos" foi garantida pela adição do herbicida aos meios de cultivo, 36 horas após a instalação do experimento, pós-estabilização do sistema e prévio suprimento dos tecidos dos explantes com Phe, Tyr e Trp. Essa medida evitou clorose e necrose dos legumes dos explantes, sem a qual a absorção e a translocação dos aminoácidos aromáticos, juntamente com a solução nutritiva destes, seriam deficientes.

O controle in situ (Figura 2) apresentou teor protéico inferior ao tratamento com glutamina mais aminoácidos aromáticos e glyphosate, tratamento esse que se comportou igualmente aos tratamentos sem glyphosate. $\mathrm{O}$ fato de o controle in situ ter apresentado teor protéico inferior ao da maioria dos tratamentos in vitro pode ser explicado por Mosquim e Sodek (1991), que especularam sobre a possibilidade de as plantas in vivo possuírem "capacidade ociosa" de biossíntese de proteínas, que pode ser amplamente explorada pelo sistema de cultivo de explantes, em virtude do fornecimento exógeno de fontes de nitrogênio e carboidratos aos meios de cultivo.

Conforme se verifica na Figura 2, o teor de óleo do tratamento com glutamina mais aminoácidos aromáticos e glyphosate não diferiu, estatisticamente, dos tratamentos com glutamina e glutamina mais aminoácidos aromáticos, que se mostraram superiores aos do tratamento com glutamina mais glyphosate. A privação de aminoácidos aromáticos, provocada pelo glyphosate, compromete a biossíntese de enzimas envolvidas na produção de carboidratos e lipídios, com conseqüente redução dos seus conteúdos.

Observa-se, na Tabela 1, que o teor de açúcares redutores é, drasticamente, reduzido nas sementes sob efeito do glyphosate, o que permite inferir que haverá diminuição da disponibilidade de acetil-CoA, cuja produção depende da quantidade disponível dos substratos glicose e frutose para a glicólise. Dessa forma, a síntese de ácidos graxos que se dá a partir de acetil-Coa é severamente afetada e, por conseguinte, a de lipídios, que são constituídos de ácidos graxos.

Os tratamentos com glutamina somente, glutamina mais aminoácidos aromáticos e glutamina mais aminoácidos aromáticos e glyphosate não diferiram entre si quanto à concentração de clorofila total $(a+b)$ (Figura 3). $\mathrm{O}$ tratamento com glutamina mais glyphosate apresentou baixa concentração de clorofila total, resultado esse similar ao de Kitchen et al. (1981), que afirmaram que o glyphosate inibe, drasticamente, a síntese do $\delta$-aminolevulinato, precursor da clorofila. Adicionalmente, de acordo com Vaughn e Duke (1986), os tilacóides de folhas verdes de soja tratada com glyphosate, tornam-se espiralados e afuncionais.

As folhas tratadas com o herbicida apresentam número reduzido de tilacóides 
TABELA 1. Teores de carboidratos de sementes oriundas de explantes de soja, cultivados em meios de cultura líquidos, por um período de 204 horas.

\begin{tabular}{ccccc}
\hline \multirow{2}{*}{ Tratamentos $^{2}$} & $\begin{array}{c}\text { Carboidratos } \\
\text { solúveis totais }\end{array}$ & Amido & Açúcares redutores & Açúcares não- \\
& $3,35 \pm 0,27 \mathrm{c}$ & $11,76 \pm 0,33 \mathrm{a}$ & $1,16 \pm 0,14 \mathrm{a}$ & $2,43 \pm 0,41 \mathrm{c}$ \\
\hline Inicial $^{2}$ & $7,45 \pm 0,21 \mathrm{~b}$ & $12,59 \pm 0,93 \mathrm{a}$ & $0,75 \pm 0,05 \mathrm{bc}$ & $6,70 \pm 0,20 \mathrm{~b}$ \\
In $_{\text {situ }}$ & $8,22 \pm 0,18 \mathrm{ab}$ & $11,99 \pm 0,19 \mathrm{a}$ & $0,79 \pm 0,01 \mathrm{~b}$ & $7,40 \pm 0,20 \mathrm{ab}$ \\
$\mathrm{A}^{4}$ & $8,10 \pm 0,01 \mathrm{ab}$ & $12,20 \pm 0,22 \mathrm{a}$ & $0,97 \pm 0,06 \mathrm{ab}$ & $7,12 \pm 0,14 \mathrm{~b}$ \\
$\mathrm{~B}^{5}$ & $9,03 \pm 0,05 \mathrm{a}$ & $3,05 \pm 0,15 \mathrm{~b}$ & $0,50 \pm 0,01 \mathrm{c}$ & $8,53 \pm 0,20 \mathrm{a}$ \\
$\mathrm{C}^{6}$ & $8,29 \pm 0,30 \mathrm{ab}$ & $11,03 \pm 0,09 \mathrm{a}$ & $0,82 \pm 0,02 \mathrm{~b}$ & $7,46 \pm 0,29 \mathrm{ab}$ \\
$\mathrm{D}^{7}$ & &
\end{tabular}

${ }^{1}$ Médias \pm erros-padrão de quatro repetições. Médias seguidas de pelo menos uma mesma letra, no sentido vertical, não diferem, estatisticamente, entre si, pelo teste de Tukey, a 5\% de probabilidade.

${ }^{2}$ Os tratamentos encontram-se discriminados na Tabela 1.

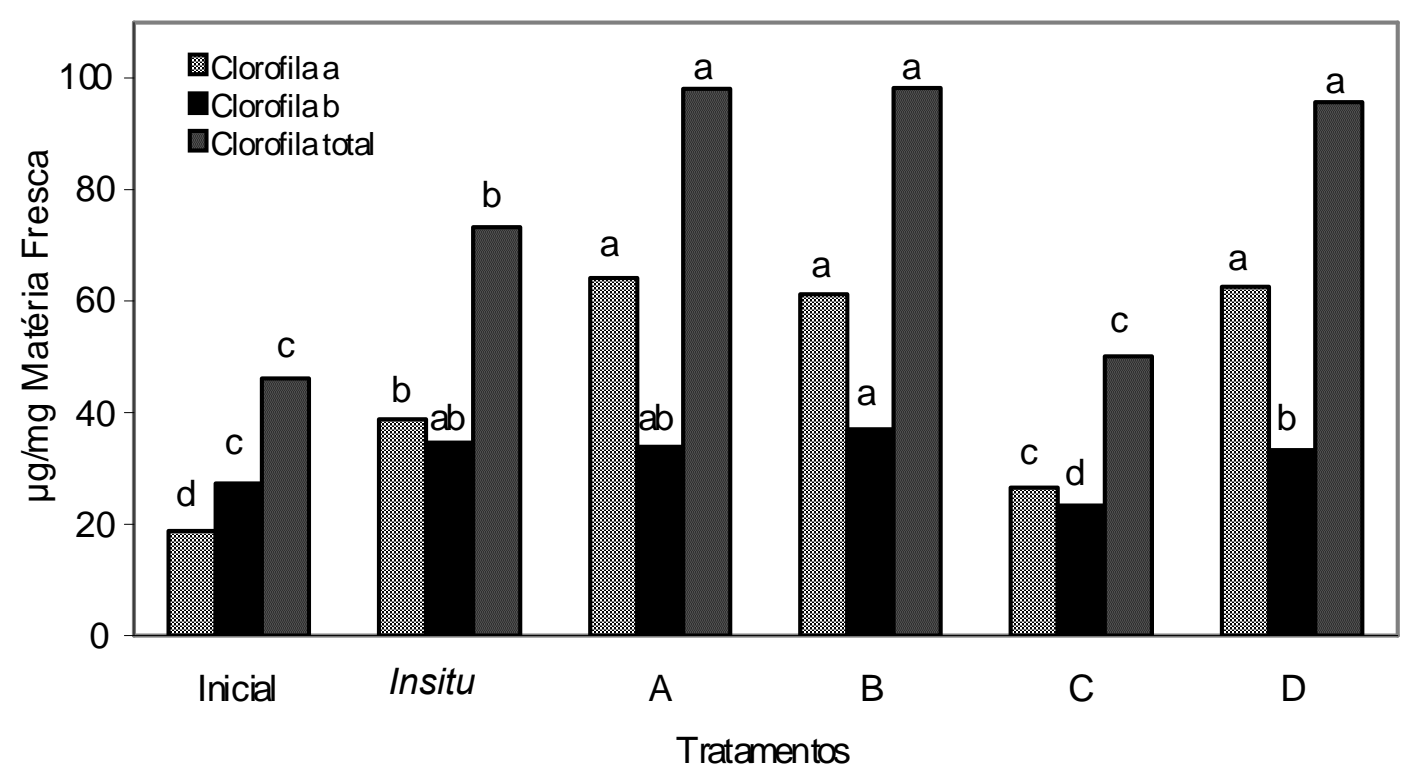

FIGURA 3. Concentrações das clorofilas $b$ e total $(a+b)$, de sementes de explantes de soja cultivados em meios de cultura por 204 horas. Barras com mesmas letras entre tratamentos não diferem entre si pelo teste de Tukey $(\mathrm{P}>0,05)$.

(Vaughn e Duke, 1986). Esse fato pode, perfeitamente, ser extrapolado para os pericarpos dos explantes, uma vez que esses são considerados folhas modificadas, do ponto de vista botânico. Foi dito, ainda, que o sítio primário de ação do glyphosate é a rota do shiquimato, contudo, aparição de clorose, especialmente nos tecidos meristemáticos, constitui-se no primeiro sintoma visual típico da ação desse herbicida. Conclui-se, então, que a clorose verificada nos pericarpos e nas sementes dos explantes de soja tratados com glyphosate pode ser explicada pela inibição da síntese do $\delta$-aminolevulinato, que é precursor da molécula de clorofila.

No que se refere aos teores relativos de ácidos graxos da fração lipídica extraída das sementes de explantes de soja (Tabela 2), o tratamento com glutamina mais glyphosate, com 
TABELA 2. Teores relativos dos ácidos graxos da fração lipídica extraída de sementes oriundas de explantes de soja, cultivados em meios de cultura líquidos, por um período de 204 horas.

\begin{tabular}{cccccc}
\hline & \multicolumn{5}{c}{ Ácidos graxos $(\mathrm{g} / 100 \mathrm{~g})^{1}$} \\
\cline { 2 - 6 } Tratamentos $^{2}$ & $\begin{array}{c}\text { Palmítico } \\
(16: 0)\end{array}$ & $\begin{array}{c}\text { Esteárico } \\
(18: 0)\end{array}$ & $\begin{array}{c}\text { Oléico } \\
\left(18: 1^{\Delta 9}\right)\end{array}$ & $\begin{array}{c}\text { Linoléico } \\
\left(18: 2^{\Delta,, 12}\right)\end{array}$ & $\begin{array}{c}\text { Linolênico } \\
\left(18: 3^{\Delta, 11215}\right)\end{array}$ \\
\hline Inicial & $12,86 \pm 0,52 \mathrm{a}$ & $4,25 \pm 0,29 \mathrm{a}$ & $18,48 \pm 0,62 \mathrm{~b}$ & $48,82 \pm 1,24 \mathrm{~b}$ & $15,58 \pm 0,39 \mathrm{a}$ \\
In situ & $10,89 \pm 0,14 \mathrm{bc}$ & $4,08 \pm 0,26 \mathrm{a}$ & $24,45 \pm 1,35 \mathrm{a}$ & $50,77 \pm 1,46 \mathrm{ab}$ & $9,77 \pm 0,66 \mathrm{~b}$ \\
$\mathrm{~A}$ & $11,15 \pm 0,18 \mathrm{bc}$ & $3,99 \pm 0,18 \mathrm{a}$ & $19,94 \pm 0,35 \mathrm{~b}$ & $53,95 \pm 0,17 \mathrm{a}$ & $10,78 \pm 0,70 \mathrm{~b}$ \\
$\mathrm{~B}$ & $10,61 \pm 0,20 \mathrm{bc}$ & $3,88 \pm 0,29 \mathrm{a}$ & $17,64 \pm 0,17 \mathrm{~b}$ & $54,32 \pm 0,90 \mathrm{a}$ & $12,53 \pm 0,51 \mathrm{ab}$ \\
$\mathrm{C}$ & $11,54 \pm 0,76 \mathrm{~b}$ & $3,67 \pm 0,04 \mathrm{a}$ & $17,78 \pm 0,95 \mathrm{~b}$ & $51,98 \pm 1,40 \mathrm{ab}$ & $15,01 \pm 1,40 \mathrm{a}$ \\
$\mathrm{D}$ & $10,34 \pm 0,03 \mathrm{c}$ & $4,35 \pm 0,26 \mathrm{a}$ & $17,62 \pm 0,14 \mathrm{~b}$ & $54,94 \pm 0,78 \mathrm{a}$ & $12,73 \pm 0,34 \mathrm{ab}$ \\
\hline
\end{tabular}

${ }^{1}$ Médias \pm erros-padrão de quatro repetições. Médias seguidas de pelo menos uma mesma letra, no sentido vertical, não diferem, estatisticamente, entre si, pelo teste de Tukey, a 5\% de probabilidade.

${ }^{2}$ Os tratamentos encontram-se discriminados na Tabela 1.

exceção do ácido linolênico que foi superior, comportou-se igualmente ao tratamento controle com somente glutamina. $\mathrm{O}$ tratamento com apenas glutamina não diferiu, estatisticamente, dos tratamentos com glutamina mais aminoácidos aromáticos e glutamina mais aminoácidos aromáticos e glyphosate. Portanto, não se deve considerar o glyphosate como um agente modificador significativo dos teores relativos de ácidos graxos da fração lipídica de sementes de explantes de soja, haja vista que não se verificou nenhum efeito evidente desse herbicida sobre essa característica.

Em relação aos teores de carboidratos solúveis totais, os tratamentos não diferiram, estatisticamente, entre si, pelo teste de Tukey, a $5 \%$ de probabilidade (Tabela 1). Os teores de amido e de açúcares redutores do tratamento com glutamina mais glyphosate mostraram-se inferiores aos dos demais tratamentos. Esses resultados são respaldados por Vaughn \& Duke (1986), segundo os quais, os tilacóides de cloroplastos de folhas verdes de soja tratada com glyphosate tornam-se espiralados (afuncionais), e o amido contido nos tilacóides é drasticamente reduzido.

Por outro lado, o glyphosate, ao inibir a atividade da EPSPS, provoca exaustão de arogenato, que é um modulador negativo da enzima 3-desoxi-D-arabino-heptulosenato-7fosfato sintase (DAHPS), que é a primeira enzima da rota do shiquimato. Essa enzima alostérica tem a função de condensar fosfoenolpiruvato (PEP) com eritrose-4-P, para produzir 3-dehidroquinato, que, em reações subseqüentes, é convertido em shiquimato-3-P (Schulz et al., 1990; Pinto et al., 1988). O glyphosate causa rápido decréscimo dos níveis de ribulose bifosfato e do ácido fosfoglicérico em células de plantas tratadas com esse produto. Esse fato sugere drenagem de carbono do ciclo de Calvin-Benson pela rota do shiquimato; com isso, há redução da síntese de frutose e, consequientemente, de carboidratos de reserva (Servaites et al., 1987). Isto explica a ocorrência de baixos níveis de amido e de açúcares redutores no tratamento com glutamina e glyphosate (Tabela 1).

O mais provável, contudo, é que a redução dos conteúdos de amido e de açúcares redutores, pelo glyphosate, nas sementes dos explantes, no tratamento contendo glutamina somente (Tabela 1), decorre da rápida necrose e senescência dos tecidos dos explantes. Esses eventos se devem mais ao bloqueio da rota do shiquimato pelo herbicida do que, especificamente, ao aumento da atividade da 3deoxi-D-arabino-heptulosenato-7-fosfato sintase (DAHPS), uma vez que os meios de cultivo foram suplementados com sacarose.

O glyphosate deve provocar interrupção da biossíntese de polissacarídeos de reserva, além de promover sua hidrólise para suprir a demanda energética dos explantes, sem, entretanto, 
prejudicar o fluxo da solução nutritiva pelo xilema. A diminuição de fluxo da solução nutritiva pelo xilema, no caso específico dos explantes, deve-se mais à necrose dos seus tecidos, com posterior ressecamento das sementes (Figura 1), do que, propriamente, ao decréscimo dos teores de amido e açúcares redutores. A suspeita acima é compatível com as asserções de Geiger et al. (1986), que sustentam que o mesmo sucede com plantas intactas tratadas com o herbicida, com a ressalva de que o fluxo de fotossintatos pelo floema é, expressivamente, reduzido em função da queda dos níveis de sacarose no interior desse vaso condutor.

Explantes sob estresse causado pelo glyphosate apresentam, provavelmente, maior consumo de açúcares redutores para obtenção de substratos a serem utilizados no processo de respiração celular, muito embora esse evento tenda a exaurir-se à medida que os tecidos vegetais são necrosados.

Quanto ao teor de açúcares nãoredutores (Tabela 1), o tratamento com glutamina mais glyphosate mostrou-se superior ao com glutamina mais aminoácidos aromáticos, não tendo diferido dos com somente glutamina e com glutamina mais aminoácidos aromáticos e glyphosate. $\mathrm{O}$ fato de o tratamento com glutamina mais glyphosate ter apresentado teor de açúcares não-redutores ligeiramente superior ao tratamento com glutamina mais aminoácidos aromáticos deve-se, possivelmente, à rápida senescência dos explantes, induzida pelo glyphosate. Nesse caso, embora os explantes tenham absorvido quantidades expressivas de sacarose contida nos meios de cultivo, estes não as hidrolisaram para obtenção de glicose e frutose, uma vez que o aludido tratamento apresentou teor de açúcares redutores inferior a todos os demais.

O tratamento com glutamina mais aminoácidos aromáticos e glyphosate não diferiu, estatisticamente, dos com glutamina somente e glutamina mais aminoácidos aromáticos, quanto ao teor de açúcares não-redutores (Tabela 1).

Com base no eletroferograma e nos conteúdos relativos dos polipeptídeos componentes da proteína total das sementes dos explantes de soja (Figura 4 e Tabela 3), nota-se que os conteúdos dos polipeptídeos $\mathrm{A}_{3} \mathrm{e} \mathrm{A}_{4}$ constituintes da proteína glicinina, sofreram queda drástica no tratamento com glutamina mais glyphosate, em relação ao tratamento com glutamina mais aminoácidos aromáticos e glyphosate. Esse último tratamento se comportou de maneira similar aos controles com somente glutamina e glutamina mais aminoácidos aromáticos. Em relação aos demais polipeptídeos, não ocorreram variações visuais perceptíveis entre o tratamento com glutamina mais glyphosate e o tratamento com glutamina mais aminoácidos aromáticos e glyphosate.

Os tratamentos comportaram-se similarmente, em relação aos conteúdos relativos dos polipeptídeos de glicinina $A_{1 \mathrm{a}}, \mathrm{A}_{1 \mathrm{~b}}$ e $\mathrm{A}_{2}$ e de lipoxigenase (LOX) (Tabela 3). Os conteúdos relativos das subunidades $\alpha$ ' e $\alpha$, componentes da proteína $\beta$-conglicinina do tratamento com glutamina mais glyphosate, mostraram-se inferiores aos dos demais tratamentos. Os conteúdos do polipeptídeo $\beta$ (componente da $\beta$ conglicinina) e dos polipeptídeos $\mathrm{B}_{1 \mathrm{a}}, \mathrm{B}_{1 \mathrm{~b}}, \mathrm{~B}_{2}, \mathrm{~B}_{3} \mathrm{e}$ $\mathrm{B}_{4}$ (componentes da proteína glicinina) foram, proporcionalmente, maiores no tratamento com glutamina mais glyphosate, em relação aos dos demais tratamentos. O tratamento com glutamina mais aminoácidos aromáticos e glyphosate, na maioria das vezes, comportou-se de forma semelhante aos controles que continham glutamina somente e glutamina mais aminoácidos aromáticos, em relação aos conteúdos relativos de polipeptídeos.

Correlações positivas e significativas (P $<0,01)$ foram encontradas entre proteína, óleo, matéria fresca, matéria seca, carboidratos solúveis totais e clorofila total (Tabela 4). Dentre as características acima relacionadas, com exceção de carboidratos solúveis totais e clorofila total, as correlações estimadas para as demais características apresentaram elevada magnitude. Foram encontradas correlações positivas e significativas entre amido e a maioria das características acima relacionadas. A correlação entre amido e carboidratos solúveis totais foi significativa e negativa. Expressivas discrepâncias em magnitude, sinal e significância foram 


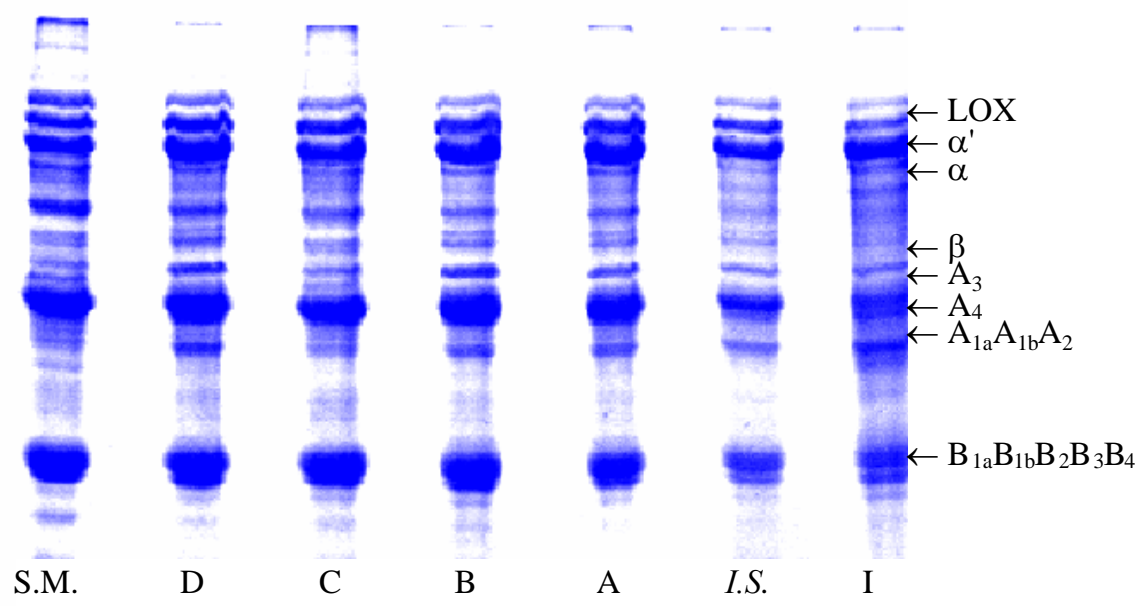

FIGURA 4. Eletroferograma dos polipeptídios componentes da proteína total de sementes de explantes de soja cultivados em meios de cultura por 204 horas. Os tratamentos obedecem à convenção anteriormente adotada, com o acréscimo de S.M., que corresponde à sementes maduras.

TABELA 3. Conteúdos relativos de lipoxigenase, peptídeos ácidos $\left(\mathrm{A}_{3}, \mathrm{~A}_{4}, \mathrm{~A}_{1 \mathrm{a}}, \mathrm{A}_{1 \mathrm{~b}}, \mathrm{~A}_{2}\right)$, peptídeos básicos $\left(B_{1 a}, B_{1 b}, B_{2}, B_{3}, B_{4}\right)$ e subunidades $\left(\alpha^{\prime}, \alpha\right.$ e $\left.\beta\right)$ da fração protéica de sementes oriundas de explantes de soja, cultivados em meios de cultura líquidos, 1por um período de 204 horas. Os resultados foram obtidos por densitometria de gel.

\begin{tabular}{ccccccccc}
\hline & \multicolumn{7}{c}{ Teores $^{1}(\%)$} \\
\cline { 2 - 9 } Tratamentos $^{2}$ & LOX & $\alpha$ & $\alpha$ & $\beta$ & $\mathrm{A}_{3}$ & $\mathrm{~A}_{4}$ & $\mathrm{~A}_{1 \mathrm{a}} \mathrm{A}_{1 \mathrm{~b}} \mathrm{~A}_{2}$ & $\mathrm{~B}_{1 \mathrm{a}} \mathrm{B}_{1 \mathrm{~b}} \mathrm{~B}_{2} \mathrm{~B}_{3} \mathrm{~B}_{4}$ \\
\hline Inicial $^{2}$ & $2,45 \mathrm{bc}$ & $4,75 \mathrm{c}$ & $18,22 \mathrm{~b}$ & $5,90 \mathrm{a}$ & $0,55 \mathrm{c}$ & $0,30 \mathrm{~d}$ & $35,67 \mathrm{a}$ & $32,15 \mathrm{~b}$ \\
In situ $^{3}$ & $1,12 \mathrm{~d}$ & $0,42 \mathrm{~d}$ & $23,57 \mathrm{a}$ & $3,00 \mathrm{~b}$ & $3,10 \mathrm{~b}$ & $2,65 \mathrm{c}$ & $35,55 \mathrm{a}$ & $30,55 \mathrm{~b}$ \\
$\mathrm{~A}^{4}$ & $3,85 \mathrm{a}$ & $9,07 \mathrm{a}$ & $19,70 \mathrm{~b}$ & $3,02 \mathrm{~b}$ & $2,52 \mathrm{~b}$ & $2,57 \mathrm{c}$ & $30,57 \mathrm{~b}$ & $28,47 \mathrm{~b}$ \\
$\mathrm{~B}^{5}$ & $2,22 \mathrm{~cd}$ & $9,05 \mathrm{a}$ & $17,90 \mathrm{~b}$ & $3,07 \mathrm{~b}$ & $4,12 \mathrm{a}$ & $4,90 \mathrm{a}$ & $30,87 \mathrm{~b}$ & $27,82 \mathrm{~b}$ \\
$\mathrm{C}^{6}$ & $3,50 \mathrm{ab}$ & $8,07 \mathrm{~b}$ & $13,00 \mathrm{c}$ & $5,87 \mathrm{a}$ & $2,95 \mathrm{~b}$ & $0,92 \mathrm{~d}$ & $28,90 \mathrm{~b}$ & $36,77 \mathrm{a}$ \\
$\mathrm{D}^{7}$ & $4,02 \mathrm{a}$ & $9,15 \mathrm{a}$ & $18,05 \mathrm{~b}$ & $3,75 \mathrm{~b}$ & $4,12 \mathrm{a}$ & $3,47 \mathrm{~b}$ & $29,32 \mathrm{~b}$ & $28,10 \mathrm{~b}$ \\
Média & 2,86 & 6,75 & 18,40 & 4,10 & 2,89 & 2,47 & 31,81 & 30,64 \\
C.V. $(\%)$ & 18,51 & 6,07 & 5,40 & 8,78 & 9,69 & 12,10 & 2,76 & 6,45 \\
\hline
\end{tabular}

${ }^{1}$ Médias de quatro repetições. Médias seguidas de pelo menos uma mesma letra, no sentido vertical, não diferem, estatisticamente, entre si, pelo teste de Tukey, a 5\% de probabilidade.

${ }^{2}$ Os tratamentos encontram-se discriminados na Tabela 1.

observadas entre os coeficientes de correlação de açúcares redutores e de açúcares não-redutores, em face das demais características avaliadas.

No que concerne aos teores de ácidos graxos, carboidratos e polipeptídeos constituintes das proteínas de reserva (Tabelas 1, 2 e 3), de modo geral, o tratamento com glutamina mais aminoácidos aromáticos e glyphosate foi análogo aos tratamentos controles contendo glutamina somente e glutamina mais aminoácidos aromáticos. O tratamento com glutamina mais glyphosate diferiu, estatisticamente, dos supracitados, em quase todos os parâmetros bioquímicos analisados. 
TABELA 4. Estimativas dos coeficientes de correlação entre características de sementes oriundas de explantes de soja, cultivados em meios de cultura líquidos, por um período de 204 horas.

\begin{tabular}{|c|c|c|c|c|c|c|c|c|}
\hline Variáveis & Óleo & $\begin{array}{c}\text { Matéria } \\
\text { fresca }\end{array}$ & $\begin{array}{c}\text { Matéria } \\
\text { seca }\end{array}$ & $\begin{array}{l}\text { Carboidratos } \\
\text { solúveis totais }\end{array}$ & Amido & $\begin{array}{l}\text { Açúcares } \\
\text { redutores }\end{array}$ & $\begin{array}{c}\text { Açúcares } \\
\text { não-redutores }\end{array}$ & $\begin{array}{c}\text { Clorofila } \\
\text { total }\end{array}$ \\
\hline Proteína & $0,9621 * *$ & $0,8871 * *$ & $0,9115^{* *}$ & $0,5492 * *$ & $0,4304 *$ & $-0,0593$ & $0,5006^{* *}$ & $0,9559 * *$ \\
\hline Óleo & & $0,9377 * *$ & $0,9666^{* *}$ & $0,5239^{* *}$ & $0,5290 * *$ & 0,0087 & $0,4712^{*}$ & $0,9861 * *$ \\
\hline Matéria fresca & & & $0,9656^{* *}$ & $0,5070^{* *}$ & $0,5704 * *$ & $-0,0673$ & $0,4665^{*}$ & $0,9203 * *$ \\
\hline Matéria seca & & & & $0,5947^{* *}$ & $0,4584 *$ & $-0,1333$ & $0,5492 * *$ & $0,9557 * *$ \\
\hline $\begin{array}{l}\text { Carboidratos } \\
\text { solúveis totais }\end{array}$ & & & & & $-0,3552 *$ & $-0,6580 * *$ & $0,9911 * *$ & $0,5098 * *$ \\
\hline Amido & & & & & & $0,6010^{* *}$ & $-0,3958 *$ & $0,5114^{* *}$ \\
\hline $\begin{array}{l}\text { Açúcares } \\
\text { redutores }\end{array}$ & & & & & & & $-0,7251^{* *}$ & 0,0216 \\
\hline $\begin{array}{l}\text { Açúcares } \\
\text { não-redutores }\end{array}$ & & & & & & & & $0,4553 *$ \\
\hline
\end{tabular}

* Significativo a $5 \%$ de probabilidade, pelo teste $\mathrm{t}$.

** Significativo a $1 \%$ de probabilidade, pelo teste $\mathrm{t}$.

Os resultados gerais obtidos são corroborados por Devine et al. (1993), que afirmam que o tratamento de tecidos vegetais com glyphosate resulta na inibição da enzima EPSPS (EC 2.5.1.19), pela formação do complexo terciário EPSPS-S-3-P-glyphosate, acarretando, dessa forma, déficit dos produtos finais da rota do shiquimato, que são os aminoácidos aromáticos e produtos fenólicos secundários, tendo, como conseqüência, falência de todo o metabolismo intermediário das plantas, uma vez que há interdependência das diversas vias metabólicas.

Em face da real necessidade de sistemas padronizados, isentos de interferências alheias aos tratamentos que, porventura, possam influenciar os resultados finais dos experimentos, foi otimizado um sistema de cultivo de explantes. Esse sistema se aplica, perfeitamente, a situações de estudos acerca do modo de ação e metabolismo do glyphosate, sobretudo em sementes de diferentes genótipos de soja, suscetíveis ou não a este herbicida.

Nos tratamentos que receberam aminoácidos aromáticos e glutamina, os explantes não apresentaram sintomas visuais típicos de intoxicação por glyphosate. A massa fresca e a massa seca das sementes não foram reduzidas, tanto quanto seus constituintes bioquímicos não foram afetados. Portanto, a suplementação exógena de aminoácidos aromáticos e sacarose suprime os efeitos tóxicos do glyphosate sobre explantes de soja. Assim sendo, os resultados obtidos dos experimentos de simulação, de certa forma, podem ser extrapolados para prognosticar o comportamento da soja geneticamente modificada diante do glyphosate.

Nesse caso, não houve exatamente reversão de tecidos lesionados pelo glyphosate. Nessa situação singular, o herbicida é adicionado 36 horas após a instalação do experimento, pósestabilização do sistema de cultivo e prévia absorção e translocação dos aminoácidos aromáticos, tratando-se mais precisamente de prevenção e supressão dos efeitos "fitotóxicos" do glyphosate sobre os explantes de soja, do que propriamente de reversão desses efeitos já manifestados.

Pela sua flexibilidade de uso, custo relativamente baixo, rapidez na obtenção de resultados com elevada reprodutibilidade e confiabilidade na condução dos experimentos sob condições controladas, o sistema in vitro de cultivo de explantes pode ser indicado para avaliações preliminares de graus de tolerância de genótipos de soja transgênica ao glyphosate e, eventualmente, em estudos sobre modos de ação e metabolismo de outros herbicidas, à semelhança do que foi realizado com o glyphosate. 


\section{LITERATURA CITADA}

ASSOCIATION OF OFFICIAL ANALYTICAL CHEMISTS - A.O.A.C. Official methods of analysis. Washington, D.C., 1975. 1094p.

BUBECK, D.M.; FEHR, W.R.; HAMMOND, E.G. Inheritance of palmitic and stearic acid mutants of soybeans. Crop Sci., v.29, p.652-656, 1989.

CHANDLER, P.M.; HIGGINS, T.J.V.; RANDALL, P.J.; SPENCER, D. Regulation of legumin levels in developing pea seeds under conditions of sulfur deficiency. Plant Physiol., v.71, p.47-54, 1983.

COLE, D.J. Mode of action of glyphosate-a literature analysis. In: GROSSBARD, E.; ATKINSON, E. (eds.) The herbicide glyphosate. London: Butterworths Publishers,1985. p. 48-74.

DEVINE, M.; DUKE, S.O.; FEDTKE, C. Physiology of herbicide action. Englewood Cliffs: PTR Prentice Hall, 1993. p.251-294.

DUKE, S.O. Glyphosate. In: KEARNEY, P.C.; KAUFMAN, D.D. (eds.) Herbicideschemistry, degradation and mode of action. New York: Dekker Publishers, 1988. p. 1-70.

DUKE, S.O.; HOAGLAND, R.E. Effects of glyphosate on metabolism of phenolic compounds. Phenylalanine ammonia-lyase activity, free amino acids, root-fed amino acids and glyphosate toxicity in soybean (Glycine max) seedlings. Weed Sci., v.29, p.297, 1981.

EUCLIDES, R.F. Manual para análise estatística e genética SAEG. Viçosa: UFV, CPD, 1982. 59 p.
FONTES, E.P.B; MOREIRA, A.M.; DAVIES C.S.; NIELSEN N. C. Urea-elicited changes in relative electrophoretic mobility of certain glycinin and $\beta$-conglycinin subunits. Plant Physiol., v.76, p.840-842, 1984.

HARRISON, L.A., BAILEY, M.R., NAYLOR, M., REAM, J., HAMMOND, D.L. The expressed protein in synthase in glyphosatetolerant soybeans, 5-enolpyruvylshikimate3-phosphate synthase from Agrobacterium sp. strain CP4, is rapidly digested and is not toxic to mice upon acute gavage administration. J. Nutr.,v.128, p.756-761, 1996.

HOAGLAND, D.R.; ARNON, D.I. The water culture method for growing plants without soil. Calif. Exp. Sta. Circ., v.347, 1950.

HODGE, J.E.; HODFREITER, B.R. Determination of reducing sugars and carbohydrates. In: WILSTER, R.C. \& WOLFRON, M.L. (eds.) Methods in Carbohydrate Chemistry, v.1, New York, Academic Press, 1962.p.380-394.

INSTITUTO ADOLFO LUTZ. Lipídeos. Normas analíticas do Instituto Adolfo Lutz: métodos químicos e físicos para análise de alimentos. 3 ed. São Paulo: IAL..., 1985. v. 1,533 p.

KITCHEN, L.M.; WITT, W.W.; RIECK, C.E. Inhibition of $\delta$-aminolevulinic acid synthesis by glyphosate. Weed Sci., v.29, p.571-577, 1981.

KITCHEN, L.M.; WITT, W.W.; RIECK, C.E. Inhibition of chlorophyll accumulation by glyphosate. Weed Sci., v.29, p.513-516, 1981.

LEA, P.J.; HUGHES, J.S.; MIFLIN, B.J. Glutamine and asparagine dependent protein synthesis in maturing legume 
cotyledons cultured in vitro. J. Exp. Bot., v.30, p.529-537, 1979.

LICHTENTHALER, H.K. Chlorophylls and carotenoids: pigments of photosynthetic biomembranes. Methods Enzymol., v.148, p.92-102, 1987.

MARGNA, J.; VAINJÄRV, T.; LAANEST, L. Different L-phenylalanine pools available for the biosynthesis of phenolics in buckwheat seedling tissues. Phytochemistry, v.28, p.469-475, 1989.

MOSQUIM, P.R.; SODEK, L. Culture of soybean fruit explants: growth conditions and efficiency of nitrogen sources for reserve protein synthesis. Plant Cell, Tissue and Organ Cult., v.27, p.71-76, 1991.

MUGNIER, J. Behaviour of herbicides in dicotyledonous roots transformed by Agrobacterium rhizogenes. J. Exp. Bot., v.39, p.1045-1056, 1988.

NELSON, N. A photometric adaptation of the Somogy method for the determination of glucose. J. Biol. Chem., v.153, p.375$380,1944$.

PINTO, J.E.B.P., DYER, W.E., WELLER, S.C.; HERRMAN, K.M. Glyphosate induces 3 dexoxy - D - arabino - heptulosonate - 7 - phosphate synthase in potato (Solanum tuberosum L.) cells grown in suspension culture. Plant Physiol., v.87, p.891-893, 1988.

SCHULZ, A.; MUNDER, T; HOLLÄNDERCZYTKO, H.; AMRHEIN, N. Glyphosate transport and early effects on shikimate metabolism and its compartmentation in sink leaves of tomato and spinach plants. $\mathbf{Z}$. Naturforsch., v.45, p.529-534, 1990.

SERVAITES, J.C.; TUCCI, M.A.; GEIGER, D.R. Glyphosate effects on carbon assimilation, ribulose biphosphate carboxylase activity, and metabolite levels in sugarbeet leaves. Plant Physiol., v.85, p.370-74, 1987.

SOMOGY, M. Notes on sugar determination. J. Biol. Chem., v.95, p.19-23, 1952.

THOMPSON, J.F.; MADISON, J.T.; MUENSTER, A.M.E. In vitro culture of immature cotyledons of soybean (Glycine $\max ($ L.) Merril). Ann. Bot., v.41, p.29-39, 1977.

VAUGHN, K.C. \& DUKE, S.O. Ultrastrutural effects of glyphosate on Glycine max seedlings. Pestic. Biochem. Physiol., v.26, p.56-65, 1986. 